\title{
History of groundwater development in the Indian Himalayas: past, present and future scenarios
}

\section{RITESH ARYA}

Aryadrillers 352, Sector 38 Chandigarh, India

aryadrillers@gmail.com

Since time immemorial, civilizations (Indus Valley, Mesopotamian, etc.) have flourished in and around rivers or water bodies, and the same at the time of flooding/flash flooding has been the cause of their destruction.

The present paper highlights the history of groundwater development in the mountains of the Indian Himalayas. The attempt is based on studying the groundwater structures developed by our ancestors since time immemorial in the form of identifying and protecting natural springs. Later, wells dug initially in the inter mountain valley region gradually shifted to the peaks of mountains in the form of manually digging wells for the forts constructed in the 16th century. Sustainability of the water source in the forts had to be developed for $24 \times 365$ hours per year. There was gradual transformation from exploring wells in the inter mountain valley regions to the top of the mountain, and this transformation could be related to the flash flooding activity in the past which might have washed out the major civilization/societies/kingdoms located on the banks of rivers or in the inter mountain valley regions.

The accuracy in the techniques for exploration and development of groundwater resources in the mountain peaks was at its peak until the early 18th century. This is evident from the wells found in all the forts located on the peaks of Banasar, Malaon, Bilaspur and Bhota visited by the author in the state of Himachal Pradesh.

This traditional science of hydrogeological exploration, however, died an unnatural death in 1815 when the tanks of the British defeated the Gorkhas in the Battle of Malaon. The ancestral science of exploration was based on sound lithological knowledge coupled with intuition (dowsing) which was the basis of our traditional scientific knowledge. After the industrial revolution, the British brought pumps with them and lifted water from rivers/springs to the peaks of the hills of Subathu, Kasauli, Dagshai and Shimla, which were in one of the oldest cantonments in the Himalayan subcontinent. The hydrogeologists of the past were not able to communicate with the new rulers. Thus language and the advent of new technology was the cause of unnatural death of the traditional water wisdom.

The scenario changed and there was major shift from developing groundwater resources to the tapping of surface water resources, and pumping machinery was developed to pump more and more water from different localities to the tops of the hills. The science of hydrogeology suffered and was almost a forgotten chapter in the mountains of the Himalayas. Until the early 1990s, the hills were considered to be devoid of groundwater resources. However, with the modernization of drilling equipment and the growing demand for water, an attempt was made to tap groundwater resources in the Himalayan region. In the first phase, Kangra Valley was identified and groundwater resources were developed there. However, later, exploration techniques were developed which were again using the traditional wisdom to locate the sites to tap groundwater resources in the mountains. Satellite imagery and geophysical methods are not at all applicable in the investigation of these groundwater resources in the mountain terrain. In 1997-1998 the first wells were explored and drilled by the author across the Indus Tsangpo suture zone. By then more than 25000 wells had been drilled in different hydrostratigraphic zones of the Himalayas identified by author in 1996 .

The history of groundwater development can therefore be summarized as science which was at its peak before the arrival of the British in 1815 in the Indian Himalayan Kingdom. This was followed by death of this science for almost 200 years. 
The ancient intuitive science of hydrogeology was again rejuvenated in 1990 when groundwater was to be developed in the hill states. With efforts by the author, the intuitive dowsing technique is today again at its peak and forms integral part of exploration for groundwater development; the author founded the company and is working on the principle of "NO Water NO Money" basis, i.e. if no groundwater is encountered after drilling, no money will be charged. Providing sustainable drinking water to the Tibetans who fled Tibet in 1959, following Chinese aggression, and settled in Sonamling Tibten Settlement in regions bordering Tibet in Leh Ladakh, was the first project undertaken by the author using this concept in 1998. The concept was sponsored by Water Aid for His Holiness The Dalai Lama to provide sustainable drinking water to 10000 migrant Tibetans residing in various camps in the high altitude cold mountain deserts of Ladakh which experience extreme climatic conditions. By 2000, the entire Tibetan community had $24 \times 365$ pure drinking water and the situation has remained the same since then. Prior to groundwater development they were forced to fetch drinking water from the Indus river (prone to flooding/silting in summer and freezing in winter) or wait for erratic water supply from the government tankers. Also, borewells have been drilled at $4725 \mathrm{~m}$ (15 500 feet) at North Polu, and artesian conditions encountered at $4356 \mathrm{~m}$ (14 260 feet) at Chuchul by the author (which helped him to enter the Guinness world record for drilling the highest well in the world), showing the sustainability of the resource using this traditional technique.

After detailed analysis of more than 20000 borewells, the author classified the Himalayas into seven hydrostratigraphic zones (hydrostratigraphic zones name coined by author) based on the dominant lithological formation and hydrogeological considerations. The author tried to conceptualise a model to explain the occurrence and movement of groundwater resources in the $\mathrm{HKH}$ range and is of the firm opinion that groundwater holds the key to solving the water problem on a sustainable basis, but also holds the key to ushering in a green revolution for the mountain community in future.

\section{REFERENCES}

http://indiatoday.intoday.in/story/The+incredible+waterman/1/1482.html

https://www.academia.edu/6423019/_Geological_evidences_-_Arya_C_Cycles_Climate_change_natural_-_Dr_Ritesh_Arya

http://www.guinnessworldrecords.com/world- records/highest-artesian-borehole 